Int. J. Environ. Sci. Tech.

(C) Winter 2006, Vol. 2, No. 4, pp. 335-342

\title{
Control of disinfection by products formation potential by enhanced coagulation
}

\author{
${ }^{1}$ A. Mesdaghinia, ${ }^{1 *}$ M. T. Rafiee, ${ }^{1}$ F. Vaezi, ${ }^{1}$ A. Mahvi, ${ }^{2}$ A. Torabian and ${ }^{1}$ A. Ghasri \\ ${ }^{1}$ Department of Environmental Health Engineering and Center for Environmental Research, School of Public Health, \\ and institute of Health Research Center, Tehran University of Medical Science, Tehran, Iran \\ ${ }^{2}$ Department of Environmental Engineering, Faculty of the Environment, University of Tehran, Tehran, Iran \\ Received 28 July 2005; $\quad$ revised 10 August 2005; $\quad$ accepted 1 November $2005 \quad$ available online 22September 2005
}

\begin{abstract}
Jar-test experiments were conducted to study enhanced coagulation effectiveness in removal of disinfection by products (DBPs) from Zayandehrud River at Isfahan Province-the center part of Iran- in 2004. In this study, the removal of suspended and colloidal particles and natural organic matter (NOM) at various coagulant doses and coagulation pHs was assessed through raw and treated water measurements of turbidity, $\mathrm{UV}_{254}$ absorbance, TOC, and dissolved organic carbon (DOC). The trihalomethane formation potential (THMFP) was also determined by a mathematical relationship with TOC. Results indicated that NOM removal was a function of coagulant type, coagulant dose, and $\mathrm{pH}$ of coagulation. In general, TOC, DOC, and $\mathrm{UV}_{254}$ absorbance removal enhanced with increasing coagulant dose. However, further increases in coagulant dosage had little effect on disinfection by-products precursors removal. Ferric chloride was consistently more effective than alum in removing NOM. Coagulation $\mathrm{pH}$ was appeared to be a determining factor for maximum NOM removal and the removal of DBPs precursors by enhanced coagulation was significantly enhanced at $\mathrm{pH}$ 5.5 in comparison with initial $\mathrm{pH}$ of water. Furthermore, it is specified that preadjustment of $\mathrm{pH}$ with sulfuric acid reduced the coagulant dosage and thus, production of sludge. The reduction in THMFP was consistent with the trends observed for DBPs precursors removal data (i.e. $\mathrm{UV}_{254}$ and TOC data).
\end{abstract}

Key words: Enhanced coagulation, NOM, disinfection, by-products, TOC removal, UV absorbance

*Corresponding Author, E-mail: rafiee78@yahoo.com

\section{INTRODUCTION}

Chemical coagulation with metallic salts has traditionally been used in water treatment for turbidity removal. However, coagulation is also capable of some degree of NOM removal, with NOM functioning as a precursor to disinfection by-products (DBPs) formation. (Krasner et al., 1995 and Singer et al., 2002). NOM is primarily composes of humic substances, such as humic acids (HA) and fulvic acids (FA) that result from decomposition of terrestrial and aquatic biomass, but it may also contain a range of organic species and microorganisms and their discharges (Gao et al., 2005 and Letterman et al., 1999). In recent years, process optimization with respect to NOM removal has gained a lot of attention. The main motivation for this is primarily concerns regarding unpleasant color, taste and odor, increased coagulant and disinfectant demands, known and unknown DBPs, re-growth in water distribution systems, and availability of hydrophobic organic and inorganic micropollutants associated with NOM (Black et al., 1996; White et al., 1997 and Gao et al., 2005). The yellow/orange color alone makes these waters unacceptable for drinking purposes, but the most concern with this has been the formation of halogenated by-products. Only some of these by-products have been identified, such as trihalomethanes (THMs) and haloacetic acids (HAAs), which are suspected to be human carcinogens (Black et al., 1996; Crozes et al., 1995 and Greyor et al., 1997). So attention to the removal of NOM from surface waters has increased in recent years. The coagulation process, as has been operated in many water treatment plants in Iran, is used primarily for the removal of turbidity, however, it is an essential method to reduce the concentration of NOM in surface waters and coagulants most commonly used are aluminum or iron salts. But removal efficiency is variable, depending on the physical and chemical characteristics of the water and the operating conditions. Optimum conditions for 
turbidity removal are not always the same as those for NOM removal (Gao et al., 2005). Generally, the coagulant dosage required for NOM removal is the controlling factor, and effective turbidity removal must still be provided during enhanced coagulation. The removal of NOM from water occurs by several mechanisms. The three mechanisms of NOM removal most commonly referred to are: (1) charge neutralization, (2) precipitation of metal - humic complexes and (3) adsorption onto metallic hydroxides floc (Cheng et al., 1995; Crozes et al., 1995 and Greyor et al., 1997). The mechanism that occurs is dependent on the operational conditions ( $\mathrm{pH}$ of the system and coagulant dose). In practice, it is likely that these operational conditions will overlap and that more than one mechanism will be responsible for NOM removal (Greyor et al., 1997 and Edzwald et al., 1999). Enhanced coagulation is the term used to define the process of obtaining improved removal of DBPs precursors by conventional treatment. The purpose of treatment technique for DBPs precursors removal is to reduce the formation of identified and unidentified DBPs. The concept of enhanced coagulation involves broadening coagulation objectives from turbidity removal to both turbidity and NOM removals. These dual objectives require modifying coagulation conditions for type of coagulant, coagulant dosage, and coagulation $\mathrm{pH}$. (Childress et al., 1999; Krasner et al., 1995; Anonymous, 1999 and White et al., 1997). But in the proposed D/ DBP Rule, enhanced coagulation is defined as the addition of excess coagulant for improved removal of DBP precursors by conventional treatment (Crozes et al., 1995 and Singer et al., 2002).

The Anonymous uses a two step process to determine enhanced coagulation requirements for a water work system. Step 1 defines the percentage of influent TOC a plant must remove based on the raw water TOC and alkalinity levels, where TOC serves as a surrogate for the identified and nonidentified DBP precursors (Table 1). Systems with good control of DBPs do not have to meet the matrix requirements, i.e., there are alternative compliance criteria to step 1 . These are based on other water quality measures indicative of DBP precursors control and include: source water TOC $<2.0 \mathrm{mg} / \mathrm{l}$, treated water TOC $<2.0 \mathrm{mg} / \mathrm{l}$ TTHM not $>40 \mu \mathrm{g} / \mathrm{l}$ and HAA not $>30 \mu \mathrm{g} / \mathrm{l}$ with the use of chlorine, Source water specific ultraviolet absorption (SUVA) $\leq 2.0 \mathrm{l} / \mathrm{mg}$.m, and finished water $\mathrm{SUVA} \leq 2.0 \mathrm{l} / \mathrm{mg} . \mathrm{m}$. (Anonymous, 1999)
Table 1: Enhanced coagulation: required TOC percent removals (USEPA, 1999)

\begin{tabular}{|c|c|c|c|}
\hline \multicolumn{4}{|c|}{$\begin{array}{c}\text { water alkalinity } \\
\left(\mathrm{mg} / \mathrm{l} \text { as } \mathrm{CaCO}_{3}\right)\end{array}$} \\
\hline $\begin{array}{l}\text { Source water TOC } \\
\text { (mg/l) }\end{array}$ & $0-60$ & $>60-120$ & $>120$ \\
\hline$>2.0-4.0$ & 35 & 25 & 15 \\
\hline$>4.0-8.0$ & 45 & 35 & 25 \\
\hline$>8.0$ & 50 & 40 & 30 \\
\hline
\end{tabular}

If a water system can not meet the step 1 criteria because of the nature of its precursor, it must perform jar tests to determine how much TOC removal can be achieved, i.e., they must define alternative performance criteria. This is termed step 2. During the jar tests in step 2, alum (or an equivalent dose of ferric coagulant) is added in $10 \mathrm{mg} / \mathrm{l}$ increments until the $\mathrm{pH}$ is lowered to a target $\mathrm{pH}$ value (based on the alkalinity of the raw water) and TOC measurements made on raw and settled waters. The alternative (Step 2) TOC removal criteria is established by determining the alum dosage when an additional $10 \mathrm{mg} / \mathrm{l}$ (or equivalent dosage for ferric coagulants) dose not decrease the TOC by at least 0.3 $\mathrm{mg} / \mathrm{l}$ or the settled water SUVA is less than 2.0 (Cheng et al., 1995; Crozes et al., 1995 and Letterman et al., 1999). The current investigation explores the use of enhanced coagulation with alum and ferric chloride in removing both turbidity and DBPs precursors. During this research which has been conducted at the Environmental Health Engineering Department of the Public Health School of Tehran University of Medical Science in 2004, NOM removal was examined in terms of the removal of TOC, DOC, and UV absorption at a wavelength of $254 \mathrm{~nm}\left(\mathrm{UV}_{254}\right)$.

\section{MATERIALS AND METHODS}

Raw water used in this investigation was sampled from the surface water of Zayandehrud River in November 2004. The water is relatively of good quality and one of the major sources of drinking water in several larg cities in Iran. The original samples were stored at $4^{\circ} \mathrm{C}$. The water had approximately neutral $\mathrm{pH}$, low levels of TOC, relatively high levels of alkalinity, and low levels of turbidity (Table 2). The sampled raw water was initially mixed thoroughly and then allowed to settle and finally the supernatant was used as the test water for coagulation experiments. 
Table 2: Raw water quality characteristics

\begin{tabular}{|l|c|}
\hline \multicolumn{1}{|c|}{ Parameter } & Value (as average) \\
\hline TOC $(\mathrm{mg} / \mathrm{l})$ & 3.15 \\
DOC $(\mathrm{mg} / \mathrm{l})$ & 2.7 \\
Turbidity (NTU) & 6.5 \\
$\mathrm{pH}$ & 7.8 \\
Alkalinity $\left(\mathrm{mg} / \mathrm{l}\right.$ as $\left.\mathrm{CaCO}_{3}\right)$ & 116 \\
UV ${ }_{254}(1 / \mathrm{cm})$ & 0.09 \\
SUVA $(\mathrm{l} / \mathrm{mg} . \mathrm{m})$ & 3.33 \\
THMFP $(\mu \mathrm{g} / \mathrm{l})$ & 187 \\
\hline
\end{tabular}

Reagent-grade alum and ferric chloride were used as the coagulants. To conduct a jar test, raw water samples were brought to room temperature $\left(20^{\circ} \mathrm{C}\right)$ prior to jar testing. In order to remove any organic matter, all beakers, bottles, glasswares used in experiments and paddles of stirrer (Jar- test equipment) were submerged in sulfochromic acid solution for one day and then rinsed with water and deionized water $(\mathrm{EC}<3 \mu \mathrm{s} / \mathrm{cm})$, respectively. $1000 \mathrm{ml}$ of the test water was added to each of the 6 one-liter beakers and a sedimentation Jar test (AZTEC Environmental control LTD) was used for mixing. Different amounts of coagulant (5-80 mg/l) were then added to each of the beakers. The solutions were stirred rapidly at $100 \mathrm{rpm}$ for $1 \mathrm{~min}$ after chemical addition, followed by two $7.5 \mathrm{~min}$ mixing periods at 40 and $20 \mathrm{rpm}$, respectively. Then the floc was allowed to settle for $30 \mathrm{~min}$. Supernatant was collected from the depth $10 \mathrm{~cm}$ below the surface of the each beaker water by a wide tip pipette and then analyzed for TOC, DOC, $\mathrm{UV}_{254}, \mathrm{pH}$, alkalinity and turbidity. Coagulant doses were evaluated at two $\mathrm{pH}$ conditions: initial $\mathrm{pH}$ of water (unadjusted) and $\mathrm{pH} 5.5$ (adjusted). Adjustment of the lower $\mathrm{pH}$ was performed by addition of $1 \mathrm{~N}$ sulfuric acid prior to rapid mixing and $\mathrm{pH}$ measurement was done by use of a pH- meter (Model E520). Analyses of TOC and DOC were conducted at the Research Institute of Petroleum Industry in Tehran and other parameters were determined at the Environmental Health Engineering Department of the Public Health School of Tehran University of Medical Science. Water samples were preserved with sulfuric acid at $\mathrm{pH}<2$. TOC and DOC were measured using a TOC analyzer (SM5310B Combustion -Infrared) (Anonymose, 1998). UV absorbance was measured using a $1 \mathrm{~cm}$ quartz cell and a UV/visible spectrometer (Lambda 25 PerkinElmerShelton) at a wavelength of $254 \mathrm{~nm}$. Before DOC and $\mathrm{UV}_{254}$ analyses, all the samples were filtered through pre-rinsed $0.45 \mu \mathrm{m}$ membrane filters (Ø47 mm- Schleicher and Schuell Micro Science). SUVA at $254 \mathrm{~nm}$ is an indicator of the humic content of water. It is a calculated parameter equal to UV absorption at $254 \mathrm{~nm}$ (expressed in $1 / \mathrm{m}$ ) divided by DOC (measured as $\mathrm{mg} / \mathrm{l}$ ) [SUVA= UVA $(1 / \mathrm{cm}) \times 100 / \mathrm{DOC}(\mathrm{mg} / \mathrm{l})($ Edzwald et al., 1985). A Hach turbidimeter was used to measure turbidity. Determination of trihalomethane formation potential (THMFP) has been accomplished after TOC measurement. In this way, a highly significant correlation between the TOC and THMFP that is: $\mathrm{THMFP}=43.78 \mathrm{TOC}^{1.248}$, where THMFP is in $\mathrm{g} / \mathrm{l}$ and TOC is in $\mathrm{mgC} / \mathrm{l}$, has been reported by various researchers (Letterman et al., 1999) and is used in this study.

\section{RESULTS}

The effect of alum and $\mathrm{Fe} \mathrm{Cl}_{3}$ doses at initial $\mathrm{pH}$ of water on the turbidity is shown in Fig.1. As shown, residual turbidity generally decreases with increasing coagulant dose, and $\mathrm{Fe}_{3}$ was superior in terms of turbidity removal at similar coagulant dosages. The results shown in Fig. 2 indicates that good TOC removal has been achieved at coagulant doses below $15 \mathrm{mg} / \mathrm{l}$ and relatively less additional TOC removals with increasing dose is observed for dosages greater than $15 \mathrm{mg} / \mathrm{l}$. Furthermore, the alum and $\mathrm{Fe}_{3}$ doses needed to meet the TOC removal requirements are illustrated in Fig. 2. The absorbance of ultraviolet radiation at $254 \mathrm{~nm}$ by natural waters is a good indicator of the concentration of NOM in water. The results of this measurement as a function of coagulant dose are presented in Fig. 3. It can be seen that, with some exceptions, the removal of $\mathrm{UV}_{254}$ absorbance increases as the coagulant dose increases.

The removal efficiencies of DOC at different $\mathrm{pHs}$ could be considered in Figs. 4 and 5. According to these Figs, the maximum removal rates attained for DOC at initial $\mathrm{pH}$ of water by use of alum and $\mathrm{Fe} \mathrm{Cl}_{3}$ are 50 and $61 \%$, respectively, whereas the similar rates at $\mathrm{pH}$ 5.5 are $62 \%$ and $67 \%$, respectively. The mean value of SUVA in this source water is $3.33 \mathrm{mg} / \mathrm{l}$. (Table 2) and SUVA values of the settled water as a function of coagulant dose are reported in Fig. 6. In Fig. 7, THMFP and $\mathrm{UV}_{254}$ values were sketched as a function of $\mathrm{Fe} \mathrm{Cl}_{3}$ dose. As shown, the decrease in THM formation potential appears to track the removal of UV-absorbing substances and both of them were reduced as $\mathrm{Fe} \mathrm{Cl}_{3}$ dose increased. 


\section{DISCUSSION AND CONCLUSION}

According to Fig. 1, residual turbidity levels are below $1 \mathrm{NTU}$ at $\mathrm{FeCl}_{3}$ doses more than 5 and alum doses more than $20 \mathrm{mg} / \mathrm{l}$. At thesedoses, thedominant mechanism of aggregation is sweep-floc coagulation (Randtke, 1988). For both coagulants, the residual turbidity spikes slightlywith increasing coagulant dose. As the $\mathrm{Fe} \mathrm{Cl}_{3}$ dose is increased from 45 to $80 \mathrm{mg} / \mathrm{l}$, the residual turbidity increases from 0.7 to $0.8 \mathrm{NTU}$. The most likely explanation for this observation is the formation of insoluble colloidal ferric and aluminum hydroxides and humate precipitates (as DOC in the raw water is converted to non-settling particulate forms) in the sub micrometer size range. Adsorption of NOM to the colloidal precipitates enhances their colloidal stability and thus increases the residual turbidity. As mentioned in the literature, the superiority of $\mathrm{Fe} \mathrm{Cl}_{3}$ in removing of turbidity at similar coagulant dosages as compared with alum is probably due to the fact that ferric chloride presents more active positive charges per dry weight unit of coagulant than hydrated aluminum sulfate. Thus, colloid destabilization and the formation of settleable flocs can both be expected to be achieved with ferric chloride at lower dosage than alum.

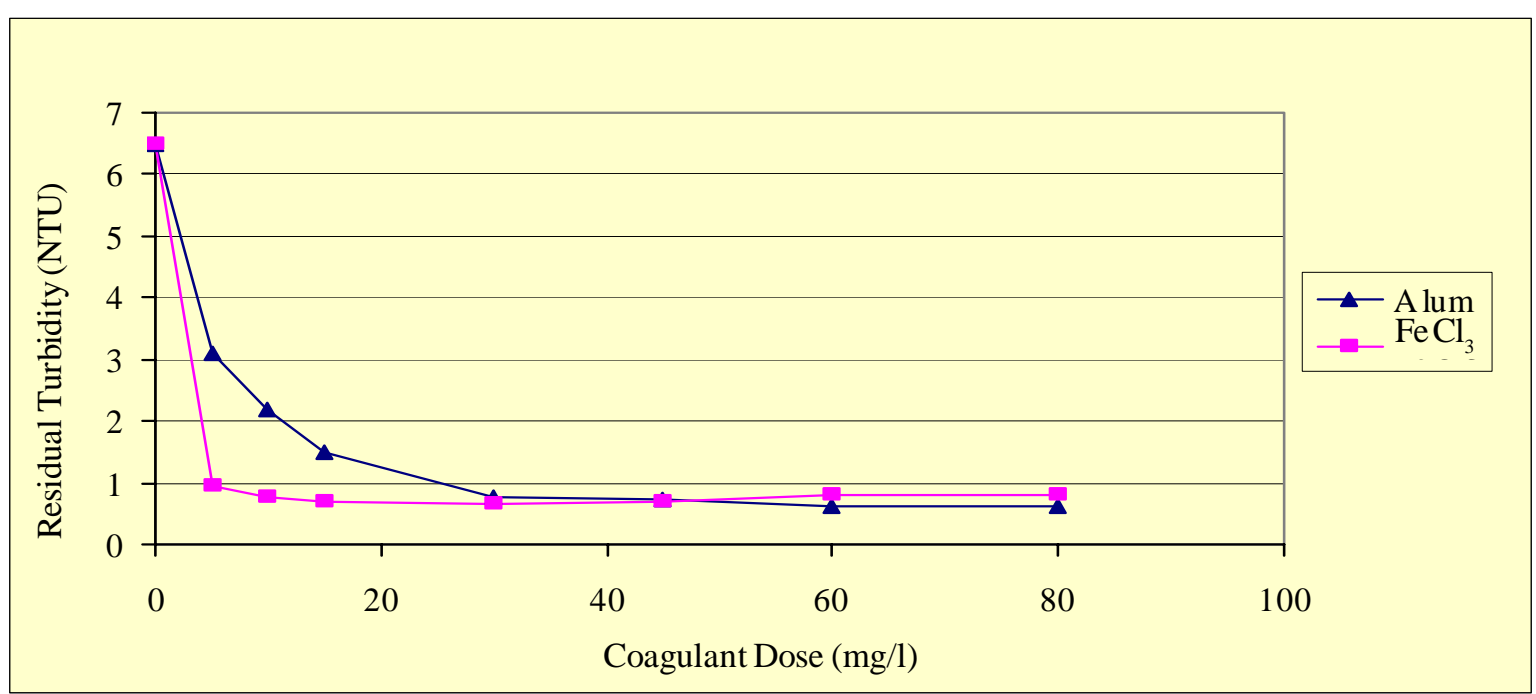

Fig. 1: Turbidity as a function of coagulant dose

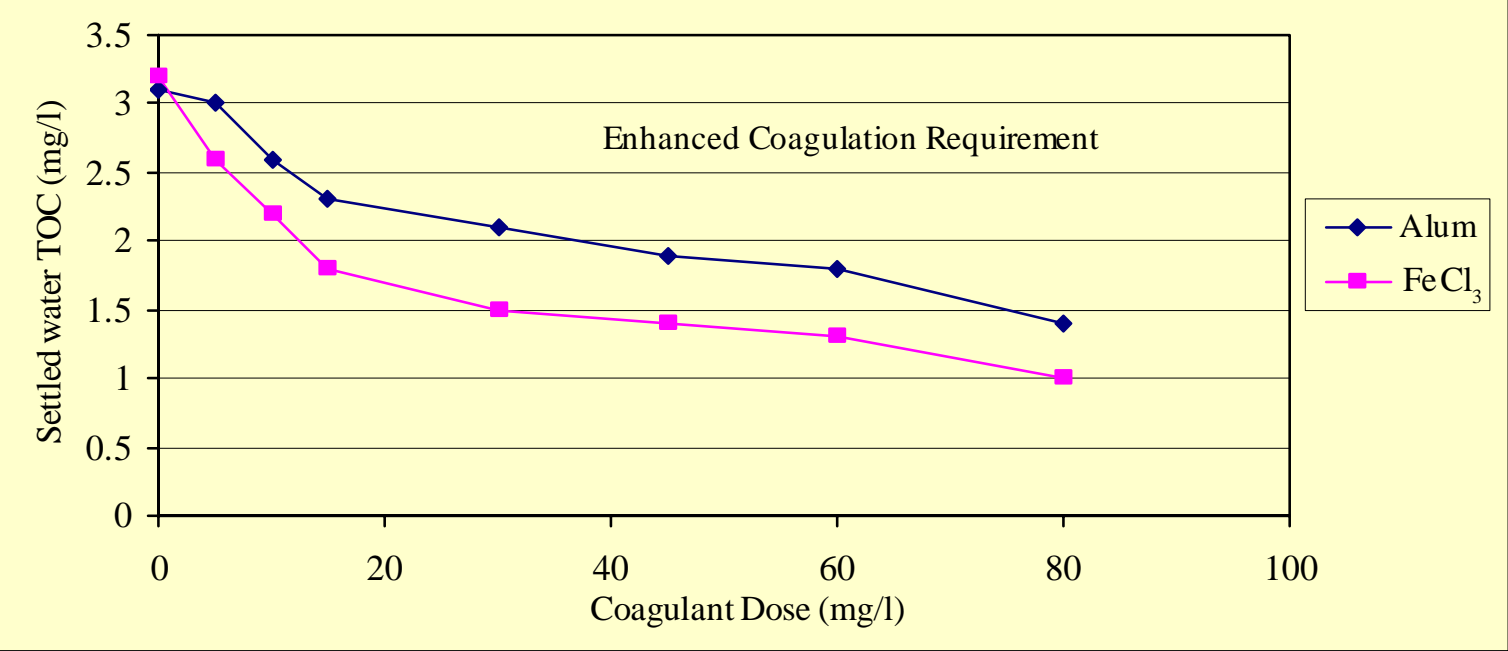

Fig. 2: TOC remaining as a function of coagulant dose 


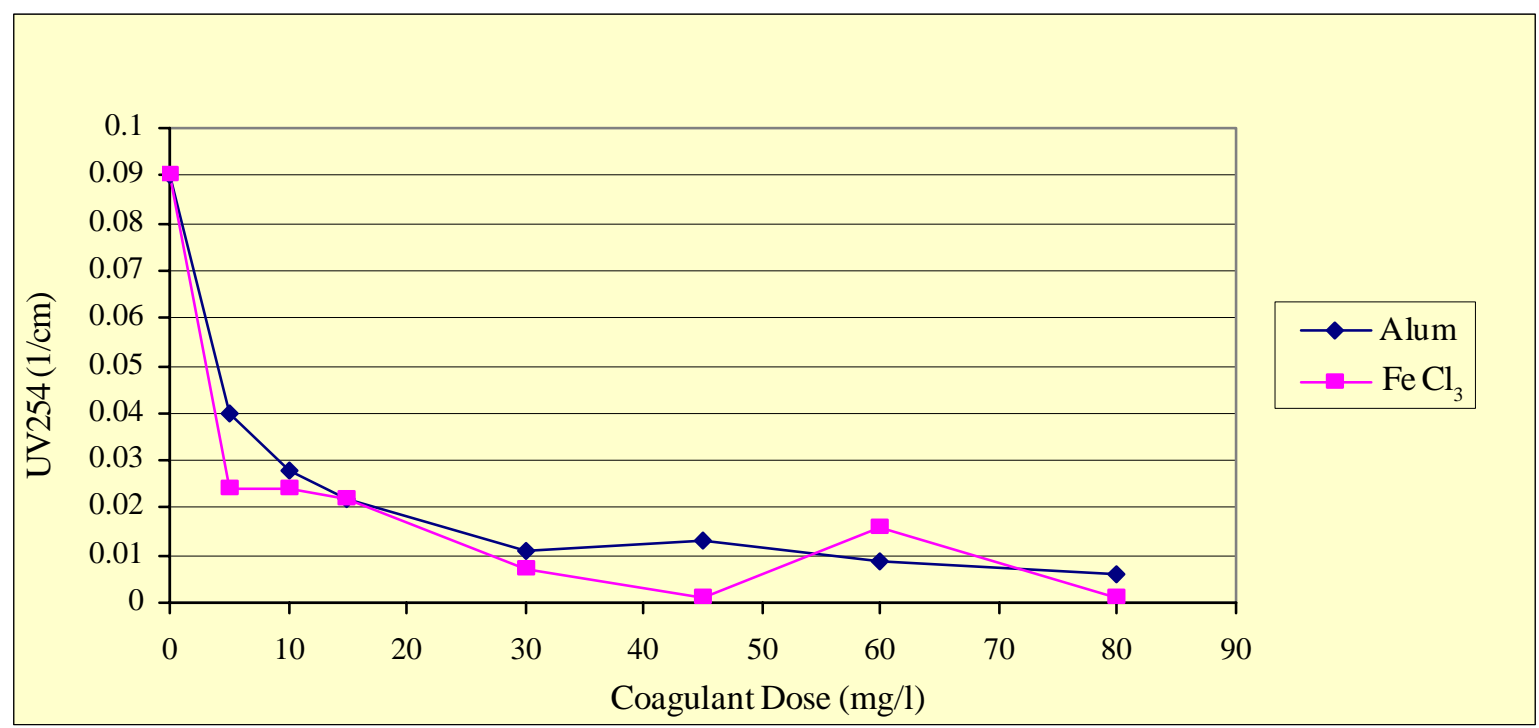

Fig. 3: Ultraviolet absorbance as a function of coagulant dose

Improvement in TOC removal and $\mathrm{UV}_{254}$ absorbance reduction is realized as coagulant dose increases. This is clearly illustrated in Figs. 2 and 3. An exception to this occurs for doses between 45 and $60 \mathrm{mg} / \mathrm{l}$ of $\mathrm{Fe} \mathrm{Cl}_{3}$ for which the reduction of $\mathrm{UV}_{254}$ absorbance decreases with increasing the dose (Fig. 3). This provides further support to the earlier supposition that small colloidal precipitates are formed during coagulation. These small precipitates scatter light in the filtered water and thus increase the $\mathrm{UV}_{254}$ absorbance reading. This same phenomenon was considered to be responsible for increased turbidity levels too. At similar coagulant dosages, ferric chloride consistently outperformed alum, although the shapes of the curves are quite similar. This is probably due to the high cationic charge of $\mathrm{Fe}_{3}$ in contrast to alum. Furthermore, ferric chloride solution is more acidic than alum solution. Also, the alkalinity consumed during the formation of the metal hydroxides is higher for ferric chloride than alum. As a result, for a similar coagulant dosage, the coagulation $\mathrm{pH}$ would be lower with ferric chloride than with alum. The lower $\mathrm{pH}$ by increasing the positive charge of the coagulant species, favors the adsorption of organics onto metal hydroxides. Thus, higher removal efficiencies for TOC and $\mathrm{UV}_{254}$ were achieved by $\mathrm{Fe} \mathrm{Cl}_{3}$ at the same condition. The required doses of alum and ferric chloride needed to meet the TOC removal requirement were 14 and $8 \mathrm{mg} / \mathrm{l}$, respectively, whereas to reach the settled water turbidity of 2 NTU (conventional treatment), $12 \mathrm{mg} / \mathrm{l}$ of alum or $4.5 \mathrm{mg} / \mathrm{l}$ of
$\mathrm{Fe} \mathrm{Cl}_{3}$ were needed for this particular sampling date. Thus, it is the coagulant dosage required for precursor removal that controls the coagulation process. Coagulation $\mathrm{pH}$ is dependent of the coagulant type and treated water sample. Because the optimal $\mathrm{pH}$ for NOM removal is around 5 (Randtke, 1988; Greyor et al., 1997; Childress et al., 1999 and Gao et al., 2005), lowering the $\mathrm{pH}$ to 5.5 enhanced the removal of TOC, DOC, and $\mathrm{UV}_{254}$ absorbance. Coagulation pH appeared to be a determining factor for maximum NOM removal and better removal was obtained at $\mathrm{pH} 5.5$ than at initial $\mathrm{pH}$ of water. Thus, it could be concluded that preadjustment of the coagulation $\mathrm{pH}$ to 5.5 reduces the required coagulant dose and hence the production of sludge. Results of other researches are also similar, for example Volk et al., (2000), reported the TOC removal improvement at lower $\mathrm{pH}$ values with alum and ferric chloride except in cold, low alkalinity, low TOC water. DOC and $\mathrm{UV}_{254}$ reduction by coagulation is highly dependent on the humic fraction of NOM in the source water. The humic fraction, which absorbs UV light at $254 \mathrm{~nm}$, is more effectively removed by coagulation than the non humic fraction. The SUVA represents the amount of NOM considered to be humic in nature (Krasner et al., 1995; Edzwald et al., 1999 and Letterman et al., 1999). Edzwald (1994) reported that SUVA values higher than 4-5 describe a relatively hydrophobic fraction which is likely to be effectively removed during coagulation. SUVA values of less than 3 indicate the hydrophilic fraction which is only slightly affected by 


\section{A. Mesdaghinia, et al.}

coagulation (Edzwald et al., 1999 and Volk et al., 2000). For this water source SUVA value was determined to be $3.33(\mathrm{mg} / \mathrm{l} . \mathrm{m})$, suggesting that the organic matter is a mixture of aquatic humics and other NOM, either hydrophobic or hydrophilic with molecular weights (MWs) ranging from low to high. Therefore, DOC removals accomplishes well and NOM influences coagulation. The SUVA in the samples generally decreases slightly with increasing coagulant dose (Fig. 6.) indicating that this source water NOM is amenable to chemical coagulation. Therefore, enhanced coagulation can be utilized as an efficient and inexpensive practice at reducing DBPs precursors for this source water.

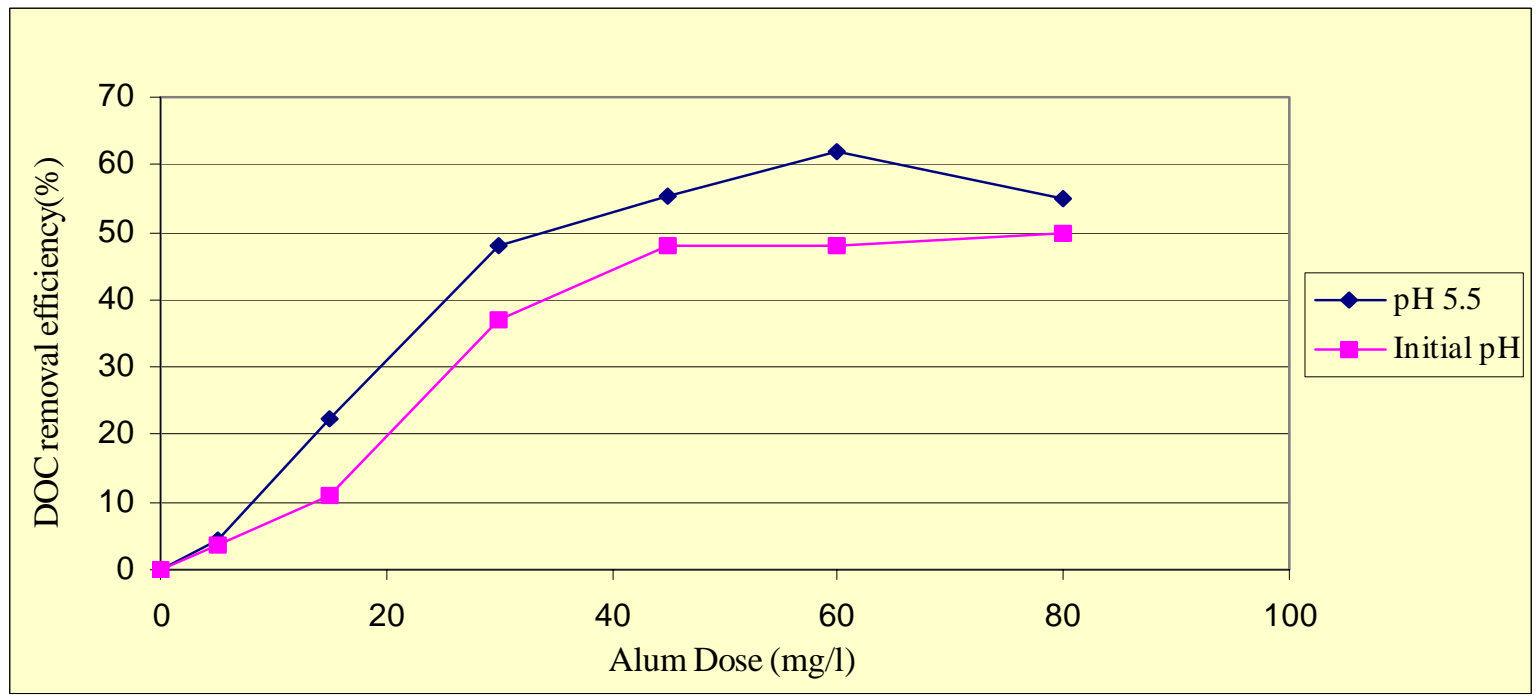

Fig. 4: Effect of $\mathrm{pH}$ on DOC removal efficiency for alum

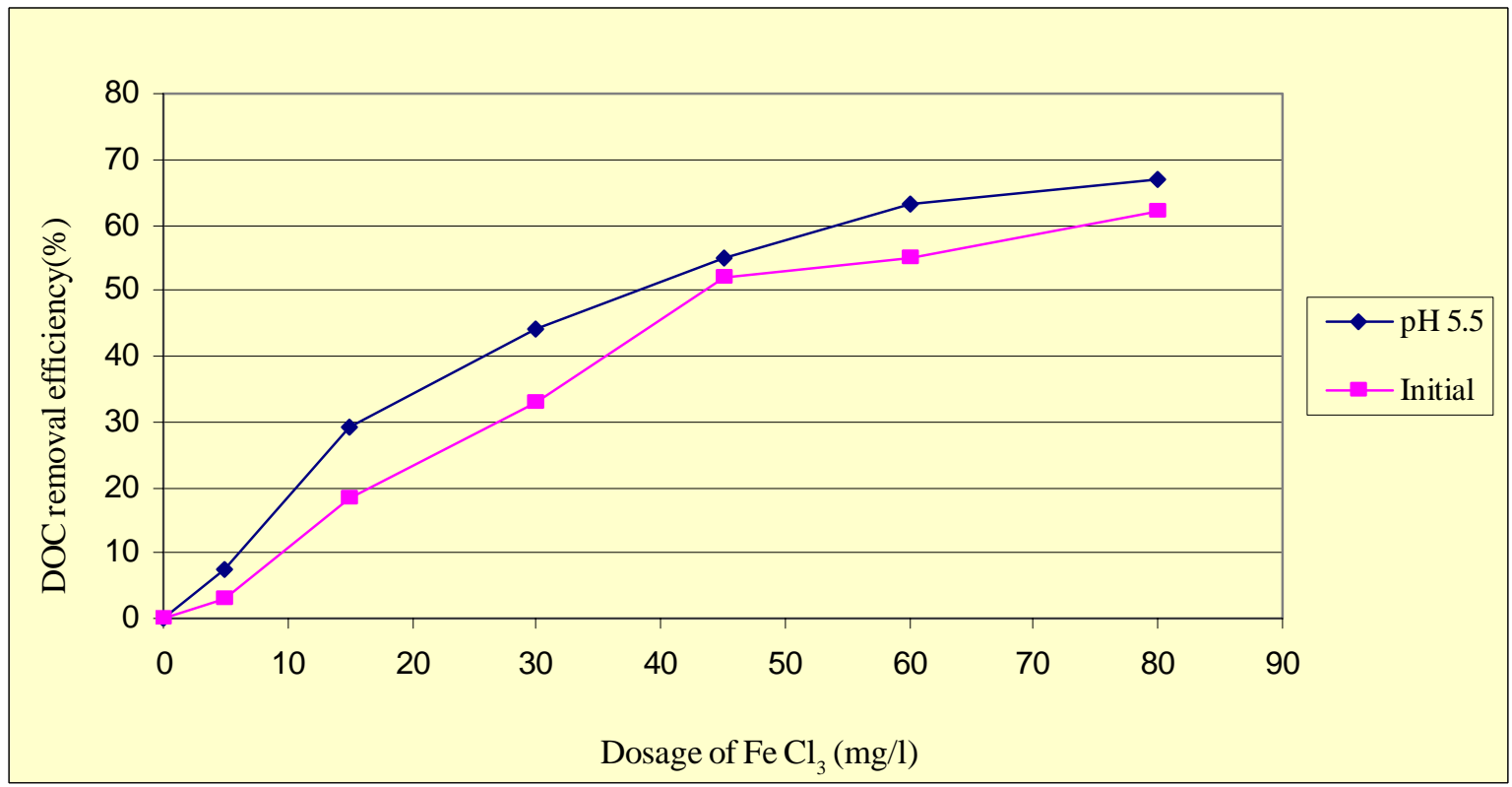

Fig. 5: Effect of $\mathrm{pH}$ on DOC removal efficiency for $\mathrm{Fe}_{3}$ 


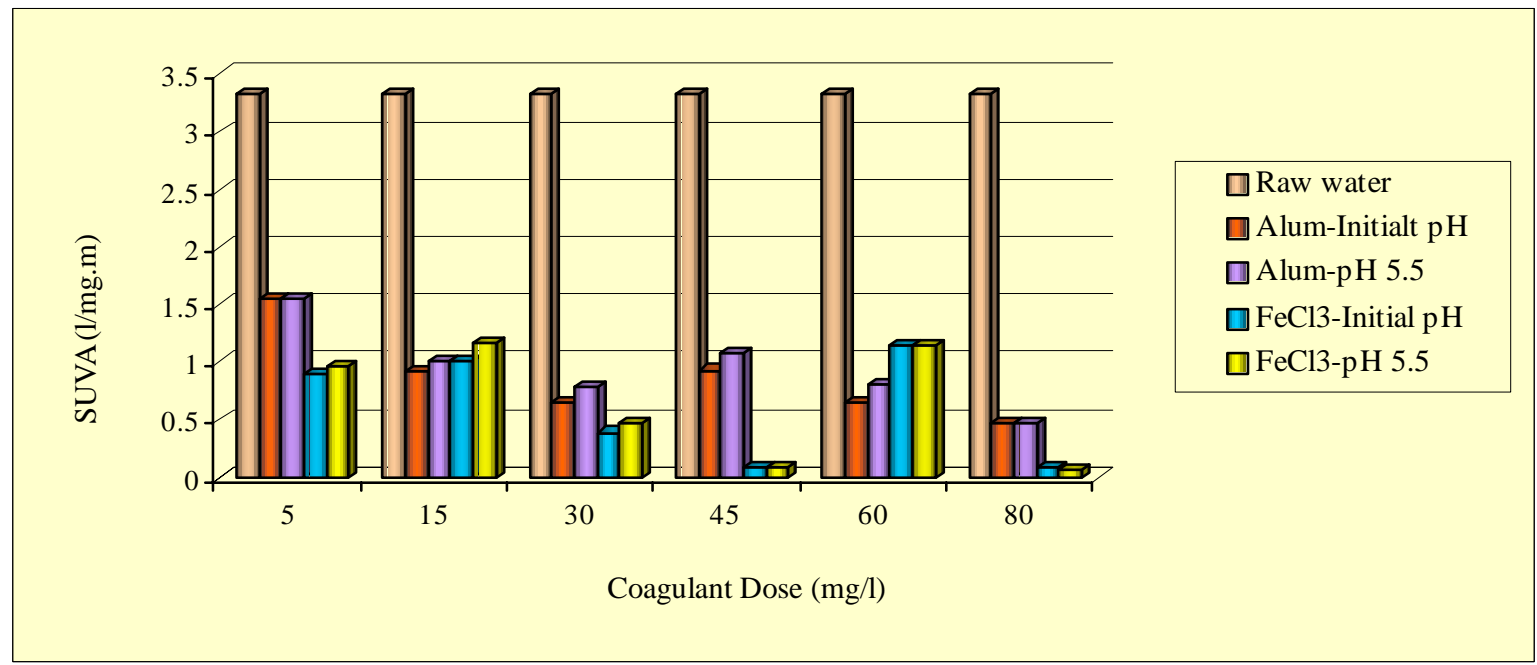

Fig. 6: Specific UV absorbance for settled water as a function of coagulant dose for raw, unadjusted and adjusted $\mathrm{pH}$ water samples

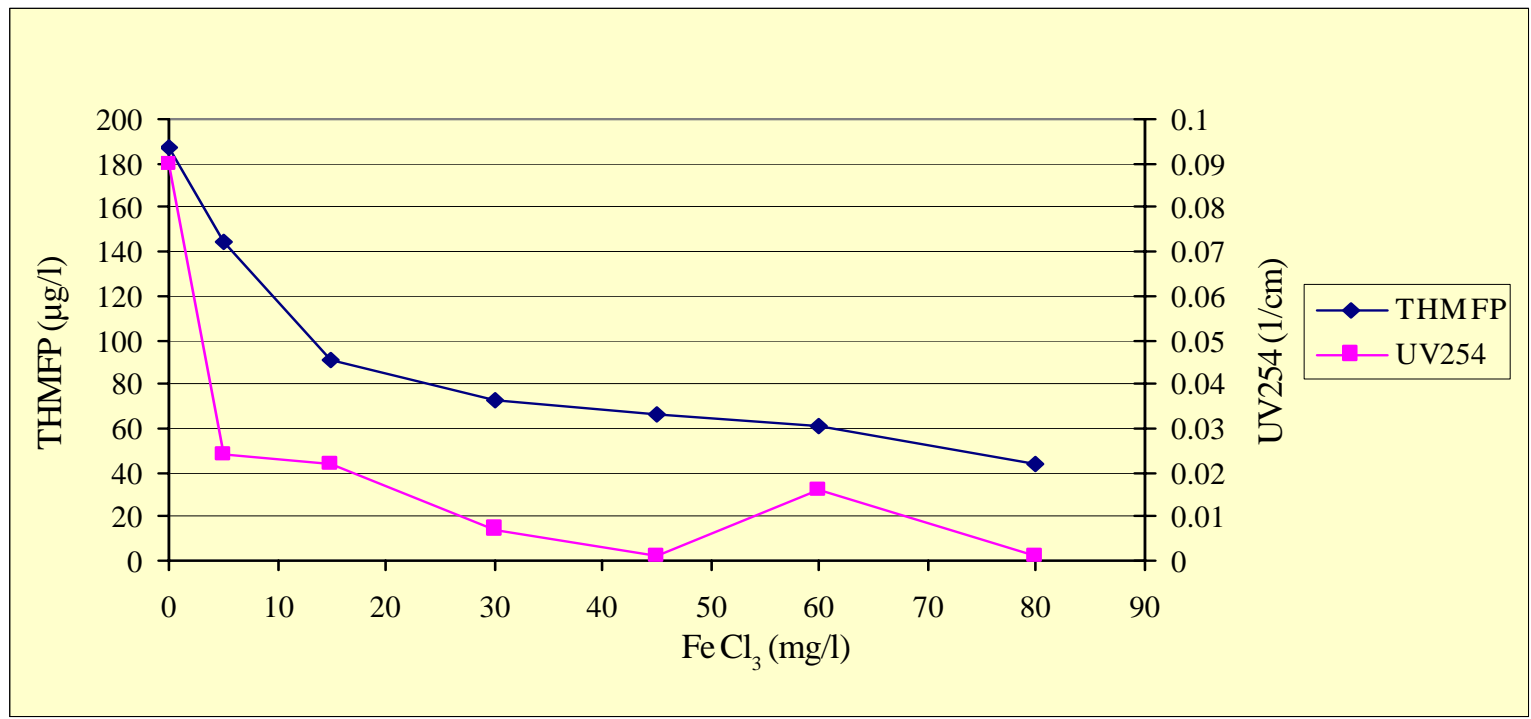

Fig. 7: THMFP and $\mathrm{UV}_{254}$ as a function of $\mathrm{FeCl}_{3}$ dose

THMFP as a function of $\mathrm{Fe}_{3}$ dose is shown in Fig. 7. As shown in this Fig, the removal of UV absorbing substances for this source water appears to track the decrease in THMFP. Thus, reduction in THMFP can be attributed to removal of THM precursors. This is consistent with the published literature which indicates that $\mathrm{UV}_{254}$ is a good surrogate for THM formation potential (Edzwald et al., 1985). In general, results of this study indicate that compared to conventional treatment, enhanced coagulation lead to additional removal of TOC, DOC, $\mathrm{UV}_{254}$ absorbance and THMFP.
The removal of NOM by enhanced coagulation depends on the type and dosage of coagulant, $\mathrm{pH}$ of coagulation and the nature of NOM. Generally, TOC and DOC removal and reduction in $\mathrm{UV}_{254}$ absorbance increased with increasing coagulant dose. However, ferric chloride proved to be consistently more effective than alum in removing NOM. Coagulation $\mathrm{pH}$ appeared to be a determining factor for maximum NOM removal and better removal was obtained at $\mathrm{pH} 5.5$ than at initial $\mathrm{pH}$ of water. Thus it could be mentioned that coagulation $\mathrm{pH}$ adjustment can reduce the required 
A. Mesdaghinia, et al.

coagulant dose and hence decrease the amount of produced sludge. The organic matter in this source water is a mixture of NOM with heterogeneous nature that is amenable to chemical coagulation and so, by influencing coagulation would be the determining factor in selecting coagulant dose, rather than turbidity. As a final conclusion, it could be concluded that enhanced coagulation can be utilized as an efficient and inexpensive tool in control of NOM and thus, reducing DBP formation potential in this source water.

\section{REFERENCES}

Anonymous (1998). Standard methods for the examination of water and wastewater, Washington, D.C., $20^{\text {th. }}$ Ed., APHA, AWWA, WEF.

Anonymous (1999). Enhanced coagulation and enhanced precipitative softening guidance manual, EPA 815-R-99-012, office Of Water, Washington D.C., USEPA.

Black, B. D., Harrington, G. W. and Singer, P. C., (1996). Impact of organic carbon removal on cancer risks posed by drinking water chlorination, J. AWWA, 88 (12), 40.

Cheng, R. C., Krasner, S. W., Green, J. F. and Wattier, K. L., (1995). Enhanced Coagulation: A preliminary evaluation, J. AWWA, 87 (2), 91-193.

Childress, A. E., Vrijenhoek, E. M., Elimelech, M., Tanaka, T. and Beuhler, M., (1999). Particulate and THM precursor removal with ferric chloride, J. Environ. Eng., 125 (11), 1054-1061.

Crozes, G., White, P., and Marshall M., (1995). Enhanced coagulation: its effect on NOM removal and chemical costs, J. AWWA, 87 (1), 78-89

Edzwald, J. K., (1994). Coagulation concepts for removal of TOC, AWWA, WQTC Conf., Nov. 6-10

Edzwald, J. K., Becker, W. C. and Wittier, K. L., (1985). Surrogate parameters for monitoring organic matter and THM precursors, J. AWWA, 77 (4), 122132.
Edzwald, J. K. and Tobiason, J. E., (1999). Enhanced Coagulation: US requirements and a broader view, Wat. Sci. Tech., 40 (9), 63-70.

Gao, B. Y. and Yue, Q. Y., (2005). Natural organic matter (NOM) removal from surface water by coagulation, J. Environmental Science, 17 (1), 124127.

Greyor, J. E., Nokes, C. J. and Fenton, E., (1997). Optimising natural organic matter removal from low turbidity waters by controlled $\mathrm{pH}$ adjustment of aluminum coagulation, Wat. Res., 31 (12), 29492958.

Krasner, S. W. and Amy, G., (1995). Jar-test evaluations of enhanced coagulation, J. AWWA, 87 (10), 93107.

Letterman, R. D., Amirtharajah, A. and O'Melia, C. R., (1999)., Chapter 6. Coagulation and Flocculation in Water Quality and Treatment, 5th Ed., American Water Works Association, McGraw Hill Inc. New York.

Randtke, S. J., (1988). Organic contaminant removal by coagulation and related process combinations, J. AWWA, 80 (5), 40-56.

Singer, P. C. and Bilky, K., (2002). Enhanced coagulation using a magnetic ion exchange resin, Water Research 36, 4009-4022.

Volk, C., Bell, K., Ibrahim, E., Verges, D., Amy, G. and LeChevallier, M., (2000). Impact of enhanced and optimized coagulation on removal of organic matter and its biodegradable fraction in drinking water, Wat. Res., 34 (12), 3247-3257.

White, M. C., Thompson, J. D., Harrington, G. W. and Singer, P. C., (1997). Evaluating criteria for enhanced coagulation compliance, J. AWWA, 89 (5), 64. 